\title{
Catalytic Spectrophotometric Determination of Picogram Amounts of Vanadium in Natural Fresh and Tap Water by Flow Injection Analysis
}

\author{
Susumu KawakUbo, Koji KaJihara and Masaaki Iwatsuki ${ }^{\dagger}$ \\ Department of Applied Chemistry and Biotechnology, Faculty of Engineering, Yamanashi University, \\ Takeda, Kofu 400, Japan
}

\begin{abstract}
A highly sensitive spectrophotometric FIA method is proposed for the determination of vanadium using the vanadiumcatalyzed oxidation of $o$-phenylenediamine with bromate at $\mathrm{pH} 4.0$ and $50^{\circ} \mathrm{C}$ in the presence of gallic acid as an activator. The same calibration graph with a linear range of $0-8 \mu \mathrm{g} \mathrm{l}^{-1}$ was obtained for $\mathrm{V}(\mathrm{IV})$ and $\mathrm{V}(\mathrm{V})$ by the proposed method. The detection limit and typical sampling frequency were $4 \mathrm{ng} \mathrm{l}^{-1}(0.8 \mathrm{pg})$ and 30 samples $\mathrm{h}^{-1}$, respectively. Iron ions of up to $5 \mu \mathrm{g} \mathrm{l}^{-1}$ and humic acid of up to $3000 \mu \mathrm{g} \mathrm{l}^{-1}$ were tolerable in the determination of $0.2 \mu \mathrm{g} \mathrm{l}^{-1}$ of vanadium; the latter value was markedly improved compared to that with a manual-batch fluorometric method. The proposed method was successfully applied to analyses of lake, river, ground, rain and tap water samples containing vanadium down to $0.02 \mu \mathrm{g} \mathrm{l}^{-1}$.
\end{abstract}

Keywords Catalytic determination, vanadium, flow injection analysis, spectrophotometry, $o$-phenylenediamine, gallic acid, fresh water, tap water

The determination of trace vanadium is important in environmental and biological studies. ${ }^{1,2}$ The combination of catalytic spectrophotometry with flow injection analysis (FIA) is quite useful for routine analyses of water samples compared with other sensitive methods, e.g., inductively coupled plasma atomic emission or mass spectrometry and graphite-furnace atomic absorption spectrometry, because it has a potential to allow high sensitivity, simplicity in operation, rapidity and low analytical cost. Many catalytic photometric FIA methods for the determination of vanadium have been described in reviews. ${ }^{2,3}$ On the other hand, the determination of vanadium down to the $0.01 \mu \mathrm{g} \mathrm{l}^{-1}$ level is required, e.g., for rain ${ }^{4}$ and tap ${ }^{5}$ water samples. This requirement is satisfied by three catalytic photometric FIA methods. ${ }^{6-8}$ Vanadium down to about $0.05 \mu \mathrm{g} \mathrm{l}^{-1}$ was determined by using the oxidation of gallic acid with bromate after separating the interfering ions by a micro ionexchange column. ${ }^{6}$ This method is reliable, but slightly tedious. A detection limit (DL) of $0.02 \mu \mathrm{g} \mathrm{l}^{-1}$ was achieved by using the vanadium-catalyzed oxidative coupling reaction of 4-aminoantipyrine with $N, N$ dimethylaniline by bromate in the presence of Tiron as an activator. $^{7}$ A DL value of $0.001 \mu \mathrm{g} \mathrm{l}^{-1}$ was obtained by an air-segmented continuous-flow system using the oxidation of Bindshedler's Green leuco base with bromate. $^{8}$ However, this method using a costly commercial auto analyzer was subjected to interference

\footnotetext{
† To whom correspondence should be addressed.
}

from iron and copper ions, and was not applied to practical analyses.

We recently proposed a highly sensitive spectrofluorometric method for the determination of vanadium using the oxidation of $o$-phenylenediamine (OPDA) with bromate in the presence of gallic acid (GA). ${ }^{4}$ In this case, GA activates the catalyzed reaction without forming oxidized GA, when an excess concentration of OPDA is present. This method realized a DL value of $0.002 \mu \mathrm{g} \mathrm{l}^{-1}(10 \mathrm{pg})$ of vanadium by a manual-batch procedure, and was successfully applied to water analysis. The present paper describes a catalytic photometric FIA method using our reaction system ${ }^{4}$ for the determination of vanadium down to $0.001 \mu \mathrm{g}^{-1}$ levels or picogram amounts. For overcoming the insufficient sensitivity in photometric monitoring, the acceleration of a catalyzed reaction was performed by the optimization of reaction variables. The proposed FIA method has been successfully applied to natural fresh and tap water samples.

\section{Experimental}

\section{Reagents}

All of the chemicals used were of analytical reagent grade. Deionized and distilled water was used throughout. A stock vanadium standard solution $\left(0.400 \mathrm{~g} \mathrm{l}^{-1}\right)$ was prepared by dissolving $\mathrm{NH}_{4} \mathrm{VO}_{3}$ (purity $\geq 99.0 \%$ ) in water. Working vanadium standard 
solutions were prepared by diluting the stock standard solution with $0.1 \mathrm{mM} \mathrm{HNO}_{3}$ before use. OPDA solutions $(7-140 \mathrm{mM})$ were prepared by dissolving the reagent in water kept at $5^{\circ} \mathrm{C}$; they were stored at $5^{\circ} \mathrm{C}$ in a refrigerator and used within $6 \mathrm{~h}$. GA solutions (1.75$28 \mathrm{mM}$ ) were prepared by dissolving the reagent in water and by mixing with a sodium acetate solution and acetic acid for adjusting the $\mathrm{pH}$ of the reaction solution. Bromate solutions $(0.35-1.4 \mathrm{M})$ were prepared by dissolving $\mathrm{NaBrO}_{3}$ in water.

\section{Apparatus}

Figure 1 shows the FIA system used in this study. PTFE tubing $(0.5 \mathrm{~mm}$ i.d.) and Daiflon connectors were used throughout. Two double plunger pumps (Nihon Seimitsu Kagaku NP-FX-1U and Sanuki Kogyo SSP DM2M-1024) and a peristaltic pump (Nippon Rikagaku Kikai PF-9) were used for propelling a carrier $\left(R_{1}\right)$ and reagent solutions $\left(R_{2}, R_{3}\right.$ and $\left.R_{4}\right)$, respectively. A valvetype sample injector ${ }^{9}(\mathrm{~S})$ comprised a six-way valve, a sample loop $(0.5 \mathrm{~mm}$ i.d.) and a bypass coil $(0.25 \mathrm{~mm}$ i.d., $0.2 \mathrm{~m}$ ). The sample volume injected was measured photometrically. ${ }^{10}$ A glass flow cell (optical path, 10 $\mathrm{mm}$ long and $18 \mu \mathrm{l}$ ) was equipped with a Shimadzu UV140-01 double-beam spectrophotometer for absorbance measurements. The signal output was recorded on a strip-chart. A reaction coil (RC) and the other coils $\left(\mathrm{C}_{1}-\mathrm{C}_{3}\right)$ were submerged in a thermostated water bath $\left(50 \pm 0.1{ }^{\circ} \mathrm{C}\right.$, unless otherwise stated) in order to control the temperature of the solution streams. The cell chamber (TC) of the spectrophotometer was kept at a constant temperature by circulating water from the water bath.

\section{Procedure}

In the FIA system (Fig. 1), the water carrier and the reagent solutions $\left(R_{1}-R_{4}\right.$ in Fig. 1) were pumped at the constant flow rates indicated in this figure. A sample solution of $200 \mu \mathrm{l}$ was introduced into the sample injector (S) by a peristaltic pump, and then injected into the carrier flow. The absorbance of the oxidized OPDA was continuously monitored at $450 \mathrm{~nm}$. A calibration graph for vanadium was constructed by plotting the height of the resulting peak signal against the concentration or amounts of vanadium injected.

\section{Results and Discussion}

\section{Optimization of FIA system}

The reaction of OPDA with bromate under previously reported conditions ${ }^{4}$ produced oxidized OPDA with the maximum absorbance at $450 \mathrm{~nm}$. Therefore, the absorbance was measured at $450 \mathrm{~nm}$. A flow rate of the carrier higher than that of the other reagent solutions was selected for preventing a decrease in the peak height due to excess dilution of the sample solution by mixing with the other solutions. The decrease in the total flow rate from 2.1 to $0.7 \mathrm{ml} \mathrm{min}^{-1}$ increased the peak height, but

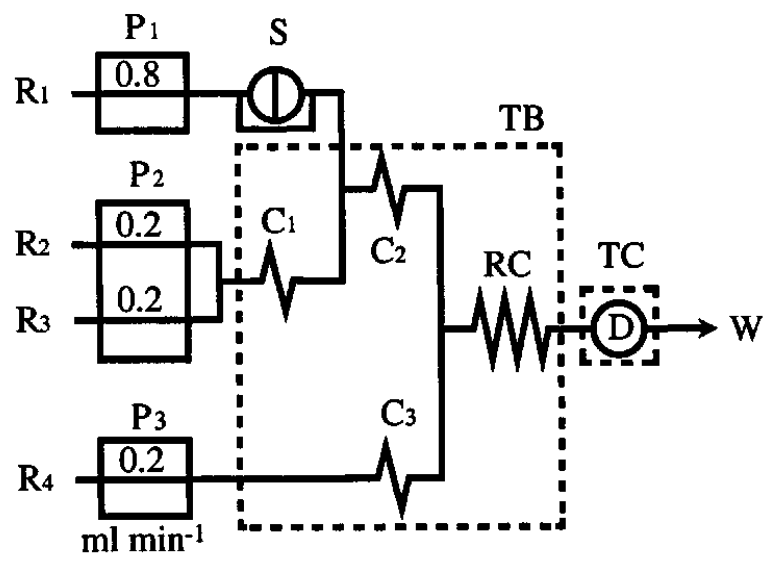

Fig. 1 FIA system. $\mathbf{P}_{1}-\mathbf{P}_{3}$, pumps; $\mathbf{R}_{1}$, water carrier; $\mathbf{R}_{2}$, $14 \mathrm{mM}$ GA solution containing $1.5 \mathrm{M}$ acetic acid and $0.35 \mathrm{M}$ sodium acetate ( $\mathrm{pH} \mathrm{4.0)} ; \mathrm{R}_{3}, 0.07 \mathrm{M}$ OPDA solution $\left(5^{\circ} \mathrm{C}\right.$ ); $\mathrm{R}_{4}, 0.7 \mathrm{M}$ bromate solution; $\mathrm{S}$, sample injector (sample volume, $200 \mu \mathrm{l}) ; \mathrm{D}$, flow cell; $\mathrm{RC}$, reaction coil $(0.5 \mathrm{~mm}$ i.d., $4 \mathrm{~m}) ; \mathrm{C}_{1}-\mathrm{C}_{3}$, coils $(0.5 \mathrm{~mm}$ i.d., $1 \mathrm{~m})$ for temperature-control of the solution streams; TB and TC, temperature-controlled water bath and cell chamber $\left(50^{\circ} \mathrm{C}\right)$, respectively; $\mathrm{W}$, waste.

increased the base-line absorbance and also decreased the sampling frequency. A total flow rate of $1.4 \mathrm{ml} \mathrm{min}^{-1}$, giving an appropriate sensitivity and a sampling frequency of 30 samples $^{-1}$, was adopted for a rapid analysis. Lengthening the reaction coil from 2 to $7 \mathrm{~m}$ increased the peak height and the base-line absorbance, but decreased the sampling frequency. A length of $4 \mathrm{~m}$ was selected to obtain a sampling frequency of 30 samples $\mathrm{h}^{-1}$ in injections of $0.2 \mu \mathrm{g} \mathrm{l}^{-1}$ of vanadium. Increasing the sample volume up to $300 \mu \mathrm{l}$ also increased the peak height, but decreased the sampling frequency. The maximum volume giving 30 samples $^{-1}$ was $200 \mu \mathrm{l}$.

\section{Optimization of reaction variables}

The photometric detection of oxidized OPDA was quite insensitive compared with fluorometric detection. ${ }^{4}$ Therefore, the acceleration of catalyzed reactions was studied for a sensitive determination. Using the FIA system shown in Fig. 1, the reaction conditions were optimized to give a higher peak height and a higher signal-to-noise ratio $(S / N)$. In this study, the $S / N$ value was evaluated from the ratio of the peak height $(S$, corresponding to $1 \mathrm{ng} \mathrm{l}^{-1}$ of vanadium) to the variation ( $N, \pm$ absorbance) of the base line. Figures $2-4$ show the effects of the reaction temperature, reagent concentrations and $\mathrm{pH}$ on the peak height for $0.2 \mu \mathrm{g} \mathrm{l}^{-1}$ of vanadium, the base-line absorbance and $S / N$. The concentrations in these figures and the following discussion represent those at the mixing point where all the reagent solutions are mixed.

Figure 2(A) shows the effect of the reaction temperature. An increase in the temperature increased the peak height corresponding to the sensitivity and base-line absorbance. On the other hand, the $S / N$ value was 

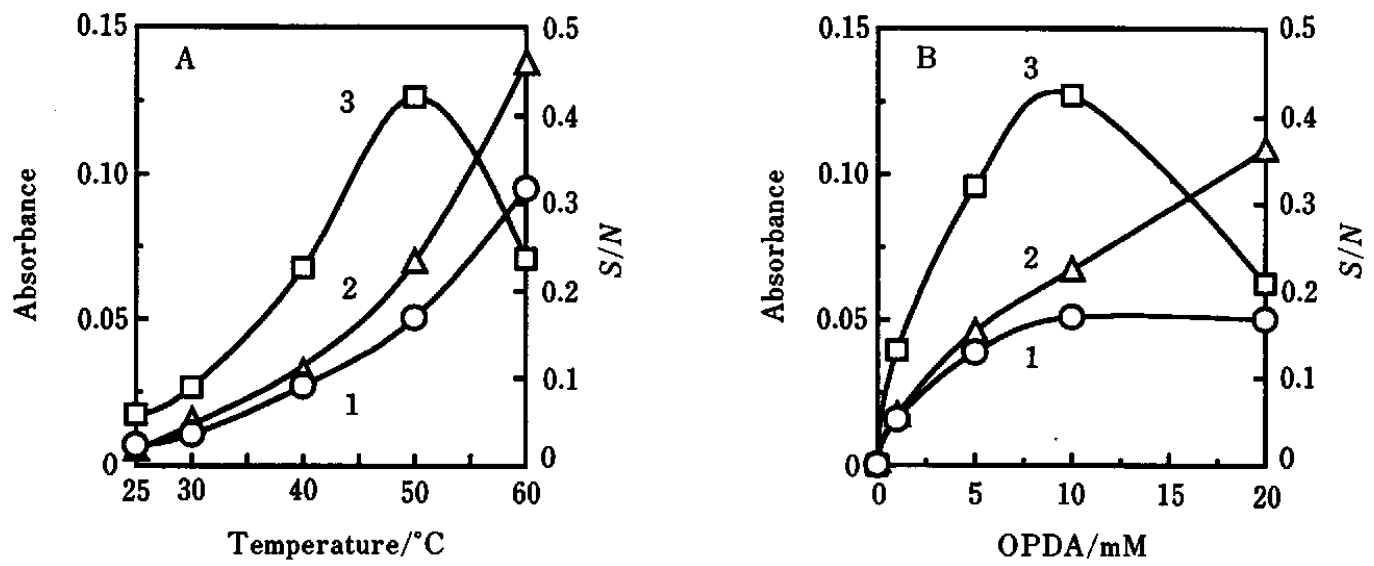

Fig. 2 Effects of the reaction temperature (A) and OPDA concentration (B) on the peak height for $0.2 \mu \mathrm{gV} \mathrm{l}^{-1}$ (1), base-line absorbance (2) and $S / N(3)$ under the conditions given in Fig. 1.
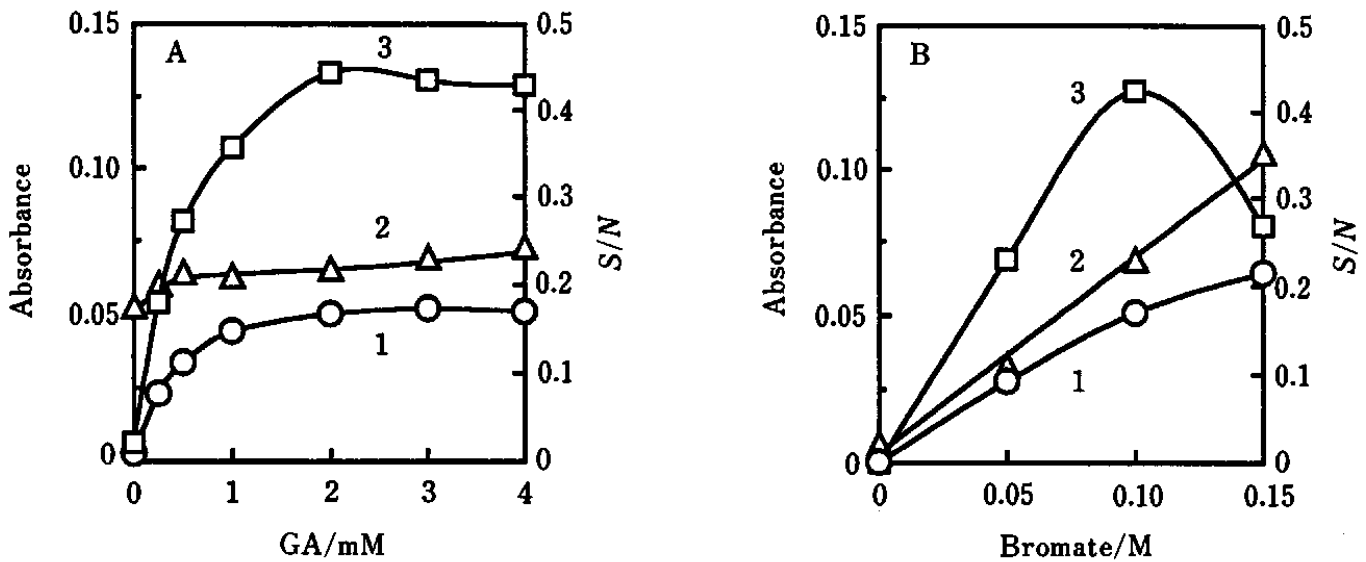

Fig. 3 Effects of the GA (A) and bromate (B) concentrations on the peak height for $0.2 \mu \mathrm{gV}^{-1}(1)$, base-line absorbance (2) and $S / N$ (3) under the conditions given in Fig. 1.

maximum at $50^{\circ} \mathrm{C}$, which was selected as the reaction temperature.

The peak height was highest in the range of $10-20 \mathrm{mM}$ OPDA, as shown in Fig. 2(B). On the other hand, an increase in the OPDA concentration increased the baseline absorbance. A concentration of $10 \mathrm{mM}$ OPDA, giving the maximum $S / N$ value, was adopted.

Figure 3(A) shows the effect of the GA concentration. A concentration of $2 \mathrm{mM}$ GA gave the highest $S / N$ value and was chosen for the subsequent experiments.

An increase in the bromate concentration increased the peak height and the base-line absorbance, as shown in Fig. 3(B). The $S / N$ value was maximum at $0.1 \mathrm{M}$, which was selected as an appropriate concentration.

For investigating the effect of the $\mathrm{pH}$ at a constant ion strength, the $\mathrm{pH}$ was adjusted by changing the concentration of acetic acid in the presence of $50 \mathrm{mM}$ sodium acetate. Figure 4 shows that an increase in $\mathrm{pH}$ markedly decreased the base-line absorbance, and that the peak height was highest in the $\mathrm{pH}$ range 3.0 to 4.0. $\mathrm{A} \mathrm{pH}$ value of 4.0 was adopted to obtain the maximum $S / N$ value. At $\mathrm{pH} 4.0$ and in the range of $25-70 \mathrm{mM}$ sodium acetate, increasing the concentration of sodium acetate and acetic acid increased the peak height, but also increased the base-line absorbance. As appropriate concentrations, $50 \mathrm{mM}$ sodium acetate and $213 \mathrm{mM}$ acetic acid, giving the maximum $S / N$ value, were adopted.

From the above results, the GA and bromate concentrations and optimized $\mathrm{pH}$ value were the same as those used for the fluorometric method. ${ }^{4}$ On the other hand, the adopted OPDA concentration and the reaction temperature were 10-times and twice higher, respectively, than those used in the fluorometric method. The 


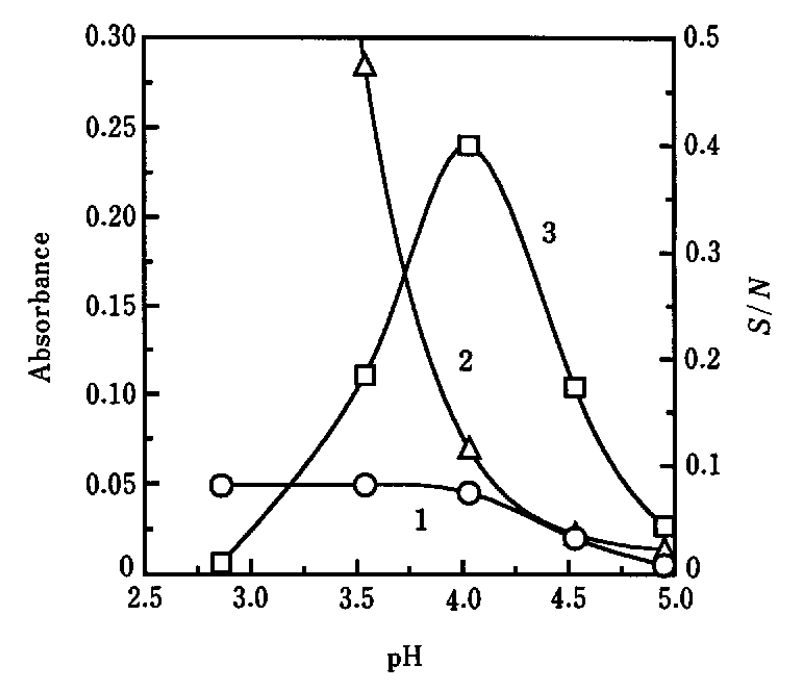

Fig. 4 Effect of the $\mathrm{pH}$ on the peak height for $0.2 \mu \mathrm{gV}^{-1}(1)$, base-line absorbance (2) and $S / N(3)$ under the conditions given in Fig. 1. Base-line absorbance was 1.38 at pH 2.9 .

present reaction conditions gave a peak height about 40 times higher than that under the previous conditions. ${ }^{4}$ In addition, in the FIA method it is convenient to use the OPDA solution, which is easily oxidized at high concentrations and temperatures and is required to be chilled for storage.

When the base-line absorbance was about 0.1 or more, an increase in the base-line absorbance significantly increased the $N$ value, i.e., the variation of the base line, and lowered the $S / N$ value (Figs. 2, 3(B) and 4). The resulting variations periodically fluctuated, due to pulsating flows from the pumps.

\section{Determination characteristics}

Under the reaction conditions optimized above, typical peak signals were recorded for different concentrations of vanadium (Fig. 5). The standard deviation $(s)$ in eight determinations of $0.1 \mu \mathrm{g} \mathrm{l}^{-1}$ of $\mathrm{V}(\mathrm{V})$ was used to estimate the DL value of vanadium corresponding to $3 s$. As shown in Table 1, the proposed FIA method realized an absolute value $(0.8 \mathrm{pg})$ of DL that was about 10-times lower than that by the previous fluorometic method. ${ }^{4}$ The relative value of DL obtained by the FIA method was $4 \mathrm{ng} \mathrm{l}^{-1}$, comparable to that by the fluorometric method and sufficient for practical analyses of natural fresh and tap water samples. The calibration graph in the FIA method has a wider linear range of concentrations of vanadium up to $8 \mu \mathrm{g} \mathrm{1}^{-1}$. This wide range was obtained by improving the reaction conditions, because the linearity was only up to $1 \mu \mathrm{g}^{-1}$ under the previous reaction conditions. ${ }^{4}$ The same calibration graph was obtained for V(IV) and V(V) by the FIA method, supporting a catalytic cycle between $\mathrm{V}(\mathrm{IV})$ and $\mathrm{V}(\mathrm{V})$, as described in a previous paper. ${ }^{4}$

A higher sampling frequency was obtained by the proposed FIA method. As shown in Fig. 5, lowering

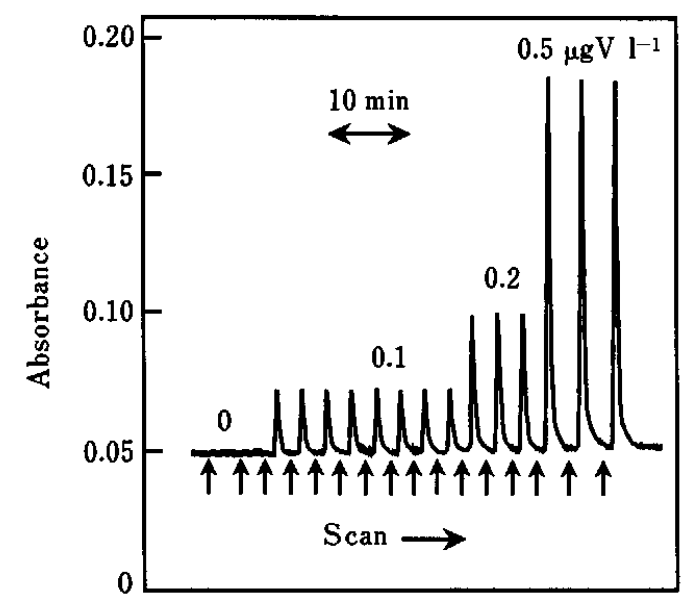

Fig. 5 Typical peak profiles for different concentrations of vanadium under the conditions given in Fig. 1. The arrows indicate the injection points.

Table 1 Comparison of the two catalytic methods for the determination of vanadium using the bromate oxidation of $o$-phenylenediamine in the presence of gallic acid

\begin{tabular}{|c|c|c|}
\hline & $\begin{array}{c}\text { Present } \\
\text { photometric FIA }\end{array}$ & $\begin{array}{l}\text { Manual-batch } \\
\text { fluorometry }\end{array}$ \\
\hline \multicolumn{3}{|l|}{ Detection limit } \\
\hline Absolute value (pg) & 0.8 & 10 \\
\hline Relative value (ng l $^{-1}$ ) & 4 & 2 \\
\hline \multicolumn{3}{|l|}{$\begin{array}{l}\text { Linear range of } \\
\text { calibration graph }\end{array}$} \\
\hline Absolute value (ng) & $0-1.6$ & $0-4$ \\
\hline Relative value $\left(\mu \mathrm{g} \mathrm{l}^{-1}\right)$ & $0-8$ & $0-0.8$ \\
\hline $\begin{array}{l}\text { Sampling frequency } \\
\left(\text { samples } \mathrm{h}^{-1}\right)\end{array}$ & $\begin{array}{l}30 \\
\left(0.2 \mu \mathrm{gV} \mathrm{l}^{-1}\right)\end{array}$ & 20 \\
\hline \multicolumn{3}{|l|}{$\begin{array}{l}\text { Tolerable limits of } \\
\text { interfering ions }\left(\mu \mathrm{g}^{-1}\right)\end{array}$} \\
\hline $\mathrm{Fe}(\mathrm{II})$ & 10 & 20 \\
\hline $\mathrm{Fe}(\mathrm{III})$ & 5 & 5 \\
\hline $\mathrm{Cu}(\mathrm{II})$ & 50 & 50 \\
\hline $\mathrm{Cr}(\mathrm{VI})$ & 20 & 5 \\
\hline W(VI) & 50 & 10 \\
\hline Humic acid & 3000 & 100 \\
\hline
\end{tabular}

Concentrations and amounts indicate those in the sample solution injected for FIA and in the reaction solution $(5 \mathrm{ml})$ for the manual-batch fluorometry. The reaction rate was used for the fluorometry.

the concentration of vanadium can shorten the tailing time of the peak signal, and, hence, increase the sampling frequency, e.g., 40 samples $^{-1}$ for $0.1 \mu \mathrm{g} \mathrm{l}^{-1}$ of vanadium. The FIA method is obviously simple and easy in the analytical operation compared with the manual-batch method.

The interference from foreign ions was investigated for $\mathrm{Fe}(\mathrm{II}), \mathrm{Fe}(\mathrm{III}), \mathrm{Cu}(\mathrm{II}), \mathrm{Cr}(\mathrm{VI}), \mathrm{W}(\mathrm{VI})$ and humic acid (HA), which interfered with the determination of 
Table 2 Determination of vanadium in water samples by the present photometric FIA (PFIA), manualbatch fluorometry (MF) and ICP-AES

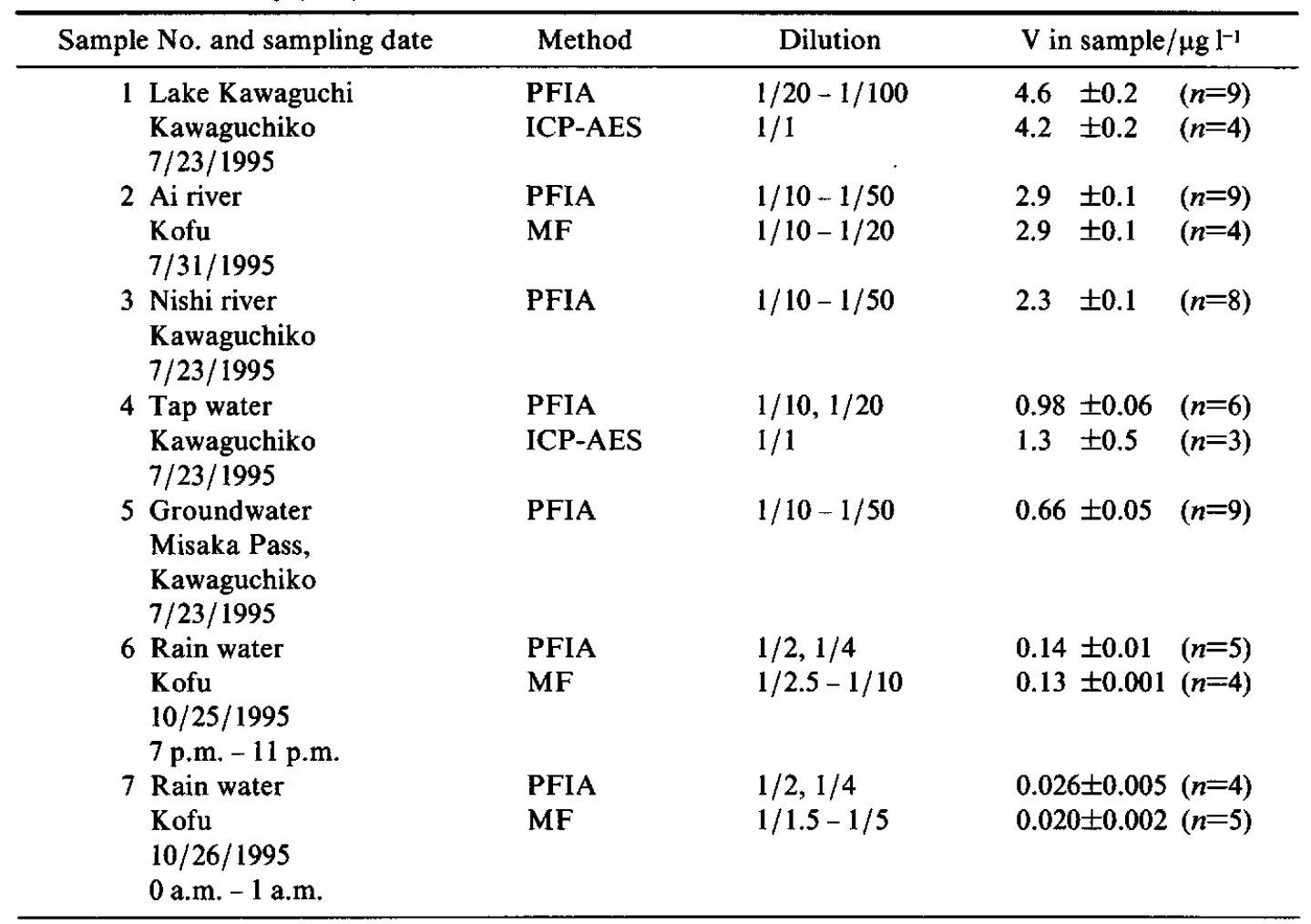

vanadium by the manual-batch fluorometric method. ${ }^{4}$ The tolerable limit was defined as the maximum concentration of a foreign ion causing about a $5 \%$ error in the determination of $0.2 \mu \mathrm{g} \mathrm{l}^{-1}$ of $\mathrm{V}(\mathrm{V})$, as in a previous paper. ${ }^{4}$ Table 1 shows that the tolerable limits of $\mathrm{Fe}(\mathrm{II}), \mathrm{Fe}$ (III) and $\mathrm{Cu}$ (II) by the FIA method were comparable to those by the fluorometric method. The tolerable limits of $\mathrm{Cr}(\mathrm{VI})$ and $\mathrm{W}(\mathrm{VI})$ were improved in the FIA method. By manual-batch photometric measurements using the previous reaction conditions ${ }^{4}$ it was found that the relative error of the determination of vanadium became small for both ions when a fixed-time (or reaction rate) method was applied, since the reaction proceeded more. The reaction used in the FIA method proceeds much more than that used in the fluorometric method, and, therefore, may be less susceptible to interference from $\mathrm{Cr}(\mathrm{VI})$ and $\mathrm{W}(\mathrm{VI})$. The positive interference from $\mathrm{Cr}$ (VI) was probably caused by its uncatalytic oxidation of OPDA. The interference from W(VI) was negative; vanadium may have been present as an inactive $\mathrm{W}(\mathrm{VI})$ complex (heteropolyacids) ${ }^{11}$ at first, and then gradually changed to an active GA complex ${ }^{4}$ upon adding GA.

The interference from HA is usually negligible in the FIA method for the practical water analysis, whereas it is considerable in the fluorometric method. The interference from HA was negative in the fluorometric method. ${ }^{4}$ Such interference properties are analogous to those for W(VI), and may be explained by the existence of an inactive vanadium-HA complex in the initial stage of the reaction. On the other hand, the interference in the FIA method was positive due to the absorption of HA at the measured wavelength. This result indicates that the formation of the HA complex is negligible under the reaction conditions used for FIA.

The interference from iron ions may not always be negligible in practical analyses, as described in a previous paper. ${ }^{4}$ The masking of iron ions with fluoride, tartrate, etc. was not successful. Therefore, dilution of the sample solution ${ }^{4}$ was adopted for eliminating the iron interference, because the proposed method is very sensitive. If necessary, an iron concentration down to about $10 \mu \mathrm{g} \mathrm{l}^{-1}$ can be easily and rapidly estimated by extraction and visual determination with 1,10-phenanthroline and thiocyanate. ${ }^{4}$

\section{Analysis of natural fresh and tap water samples}

Lake, river, ground, rain and tap water samples were collected in Yamanashi Prefecture, Japan. Two rain water samples were collected in a continuous rain-fall event. In order to eliminate particulate matter, each $100 \mathrm{ml}$ of the sample solutions was centrifuged at about $1000 \mathrm{~g}$ for $15 \mathrm{~min}$ and supernatant solutions were taken for analysis by the proposed FIA method. The degree of dilution of the sample solution was determined from the iron contents obtained by the visual method, although iron ions were undetectable for the rain water samples. For a comparison, the vanadium contents were also determined by inductively coupled plasma atomic-emission spectrometry (ICP-AES) with a DL 
value of $1 \mu \mathrm{g} \mathrm{l}^{-1}$ or by the manual-batch fluorometric method. ${ }^{4}$

Table 2 shows the results of a determination of vanadium. The recoveries of vanadium ( 20 or $40 \mathrm{pg}$ ) added to the samples of Nos. 1 and 3 were $100-105 \%$, which were acceptable regarding the analytical precision. The results obtained by the proposed method agreed with those by ICP-AES or the manual-batch fluorometric method. A vanadium content at a $0.01 \mu \mathrm{g} \mathrm{l}^{-1}$ level was determined for a rain water sample.

\section{References}

1. G. J. Keeler and P. J. Samson, Environ. Sci. Technol., 23, 1358 (1989).

2. M. J. C. Taylor and J. F. van Staden, Analyst [London], 119, 1263 (1994).

3. D. Chen, M. D. Luque de Castro and M. Valcárcel,
Analyst [London], 116, 1095 (1991).

4. S. Kawakubo, K. Ogihara and M. Iwatsuki, Analyst [London], 120, 2719 (1995).

5. Y. Sakai, K. Ohshita, K. Tomura and S. Koshimizu, Bunseki Kagaku, 43, 919 (1994).

6. T. Fukasawa, S. Kawakubo, T. Okabe and A. Mizuike, Bunseki Kagaku, 33, 609 (1984).

7. S. Nakano, M. Tago and T. Kawashima, Anal. Sci, 5, 69 (1989).

8. M. Sugiyama and T. Hori, Anal. Chim. Acta, 261, 189 (1992).

9. J. Růžička and E. H. Hansen, "Flow Injection Analysis", p. 108, Wiley-Interscience, New York, 1981.

10. S. Kawakubo, M. Iwatsuki and T. Fukasawa, Anal. Chim. Acta, 282, 389 (1993).

11. C. G. Papadopoulos and G. S. Vasilikiotis, Mikrochim. Acta, 1985 III, 31.

(Received November 27, 1995)

(Accepted January 22, 1996) 